\title{
Monitoring the AIDS Response: How Can Lessons from the Pre- 2015 Era Inform Monitoring Progress Towards Ending the AIDS Epidemic by 2030?
}

\author{
Peter D. Ghys ${ }^{1} \cdot$ Paul Bouey $^{2} \cdot$ Raymond Yekeye $^{3} \cdot$ Taavi Erkkola $^{1} \cdot$ \\ Jude Padayachy ${ }^{1} \cdot$ Daniel Low-Beer $^{4}$
}

Published online: 25 February 2017

(c) Springer Science+Business Media New York 2017

Over the past few decades the world has witnessed the evolution of the HIV epidemic, from the initial reports on AIDS in 1982, through its rapid expansion with devastating global impacts, through the most recent period during which AIDS-related mortality and new infections among children have declined faster than new infections among adults [1]. At the SDG meeting in September 2015 the global community committed to ending the AIDS epidemic by 2030 [2], and at the High Level Meeting on HIV and AIDS in June 2016 this same community aimed to reduce new infections to less than 500,000 by 2020 [3]. Modelling analyses underlie these commitments, demonstrating that major reductions in HIV incidence and AIDS-related deaths by $80-90 \%$ are possible by 2030 [4]. The global community has taken a strong commitment to build on the past momentum and realise these goals.

As we look ahead, many lessons are to be learned from the past AIDS response. Some of the major contributions over the past decade and a half of leadership, advocacy, financing, country ownership, partnerships, civil society, rights and social justice, science and data have already been highlighted recently [5]. Across this time frame, the AIDS response has grown in maturity and sophistication, built on robust collaboration and singular purpose. The science of HIV has grown and dramatically influenced our

Peter D. Ghys

Ghysp@unaids.org

1 Joint UN Programme on HIV/AIDS (UNAIDS), Geneva, Switzerland

2 Save the Children, Washington, DC, USA

3 National AIDS Control Programme, Harare, Zimbabwe

4 World Health Organisation, Geneva, Switzerland understanding of the impact of available interventions, and epidemiological and monitoring data have been a foundation of the entire response to the epidemic.

Data on the changing epidemiology have been important to shape and target programmes to where HIV transmission is most intense and to leave nobody behind [6]. Programmatic data have served the ongoing management of specific responses and allowed for adaptation and realignment of the programmatic effort. In the aggregate, data have been instrumental to the progress, accountability and success of the entire global AIDS response. The HIV response has been able to translate commitments into funding, programmes and results. The current supplement aims to bring together papers on the approaches, indicators and data systems that have been used to monitor the AIDS response to date.

The first two papers describe how UNAIDS (including WHO, UNICEF and other co-sponsors), and The Global Fund to fight AIDS, Tuberculosis and Malaria have defined indicators and designed data collection systems and reporting mechanisms to ensure accountability within their respective results frameworks and distil lessons for future monitoring $[7,8]$.

A second set of papers takes a country perspective on monitoring the AIDS response, covering Nigeria, Ukraine, and the United Kingdom [9-11]. Countries with different types of epidemics and different health systems have rightfully adapted the global frameworks to their local situation, providing a tailored system consistent with their epidemics. The ability to translate global commitments and targets into country accountability has been a critical part of the AIDS response.

Topic-specific papers describe the monitoring of the care CASCADE, of programmes for the prevention of mother-to-child transmission, and of programmes for key 


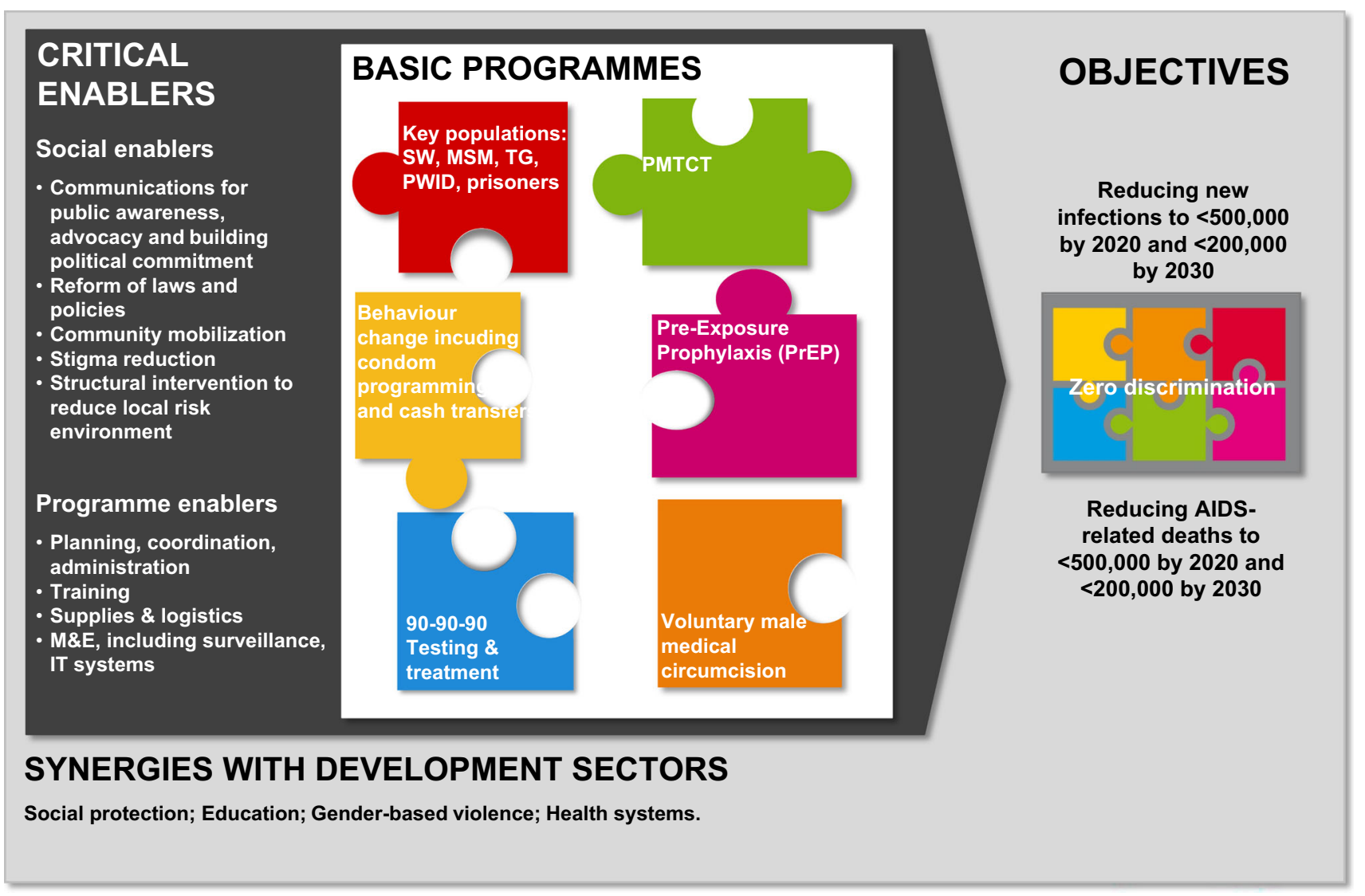

Fig. 1 Fast-Track programmatic framework. $S W$ sex workers, $M S M$ gay and other men who have sex with men, $T G$ transgender persons, $P W I D$ people who inject drugs, PMTCT prevention of mother-to-child-transmission

populations [12-14]. In all three areas, a shift towards using large amounts of routinely available programmatic data is apparent.

Two further papers investigate social enabling factors [15] and the role that civil society has played in monitoring and keeping governments accountable [16]. The two papers emphasize the critical need to monitor programmes addressing structural factors and the evolving role of civil society organisations in the monitoring of the AIDS response.

Papers with a future focus include the rationale to expand the scope of monitoring to older people, since people living with HIV age thanks to the life-extending effects of antiretroviral treatment [17]. And a second paper from Brazil explores the use of social media data to assess levels of discrimination and of campaign-related HIV testing [18].

These papers illustrate some of the key dimensions of how improved access to and use of data have unlocked the real potential for an accelerated and more effective response to the HIV epidemic. The implications of these trends for monitoring the AIDS-related SDGs through 2030 are many and can be characterized by the increasing utilization of data both for local, country and global monitoring. Data have also been used to highlight age, sex and key population characteristics; this needs to be intensified, so that no group is left behind, however marginalised. An expanding volume of data has accrued tremendous benefits, while associated analytical techniques are evolving similarly. There has also been a cost to data collection, and it is important to rationalise measures and to focus them on impact, as has been the case with the SDGs. Through these intertwined processes, we are learning how to use data more effectively and which data offer greater utility. The highest potential for improved data utilization exists at the country and local level where responsibility rests for epidemic responses and where more data can be used to align programming for the greatest impact. At the global level, data dependencies are not tied to the same level of detail, but some of these enhancements are necessary to monitor the global epidemic and response more effectively. This differential between country and global represents an important distinction in the data realm, and it is a balance that must be mastered particularly as the 'data revolution' continues. 
Anticipated changes in the monitoring realm are founded on the country and community principles of ownership which were established in the pre-2015 era and will be even more relevant for the coming era. There will need to be a local focus on leaving no populations behind and global focus on impact. Future monitoring will need to encompass an approach focused on populations and locations, highlighting the increasing need for granular epidemiological and programmatic data to ensure relevance and efficiency. A greater focus on the top indicator for monitoring progress against the AIDS-specific SDG target, i.e. HIV incidence, also requires adjustments. Over time, new HIV infections will become rarer and more concentrated in specific populations groups and locations. This transition will require the development of epidemic tracking tools that are capable of monitoring this new situation. In the future there also will be a need to monitor recently added programmatic approaches in an ongoing manner to inform decisions on their implementation, e.g. pre-exposure prophylaxis and treatment as prevention, as well as future approaches, e.g. long-acting antiretrovirals for PrEP and treatment, a vaccine, and a cure when these become available for implementation.

The monitoring framework for the Fast-Track approach endorsed in the 2016 HLM Political Declaration needs to encompass systems and indicators for the main programme elements (Fig. 1), besides critical enablers and synergies with other development sectors. Inspired by the 90-90-90 target for testing and treatment [19-21], recent work has proposed CASCADE analyses for monitoring and managing primary prevention programmes [22]. In addition, future monitoring will need to harness the power of new technologies, allowing the electronic collection of data from all health facilities and all community-based service delivery platforms as well as from commodity distribution systems (e.g. for antiretroviral drugs and condoms) and their processing, analysis and dissemination in appropriate formats. Tapping into new data sources such as data generated by apps targeted at specific key populations [23] and apps owned by civil society to track in real time the availability and quality of services [24] will play a critical role in service delivery improvements and in epidemic monitoring. These advances will need to be integrated into cross cutting platforms for example district health information systems, to support routine reporting and data use. Future monitoring will also need to integrate more closely available information of the reach and coverage of programmes with data on the cost of their delivery, to inform the optimisation of the cost-effectiveness of the response.

As this past decade and a half of monitoring the HIV epidemic has clearly demonstrated, data will continue to have critical importance to country and global responses, and data-the content, processes, and analytics-will continue to evolve across all dimensions. Staying abreast of these changes is vital to the global effort, and this is a key responsibility within the larger UN mandate. Historically, UNAIDS has managed a variety of processes involving stakeholders from across the world, and these efforts have ensured the implementation of standards in data collection and metrics, harmonization among a range of stakeholders, and collective efforts to improve and strengthen efficiencies in the data collection and management processes. As these collaborations continue, work will proceed in concert with larger frameworks supported at the global level, including PARIS21 [25], and the Health Data Collaborative [26], among others.

As this supplement illustrates-with past achievements and awareness of the effectiveness of currently available approaches, and the prospect of additional tools that will become available in the near future-the world should be confident that the reduction of HIV incidence and the programmes that drive it down can be targeted and well monitored by tested existing systems, and expansions and innovations that build on them.

\section{References}

1. UNAIDS. Prevention Gap Report. UNAIDS, Geneva; 2016.

2. United Nations. Transforming our world: the 2030 Agenda for Sustainable Development. New York; 2015.

3. United Nations. Political Declaration on HIV and AIDS: On the Fast-Track to Accelerate the Fight against HIV and to End the AIDS Epidemic by 2030. New York; 2016.

4. Stover J, Bollinger L, Izazola JA, Loures L, DeLay P, Ghys PD, et al. What is required to end the AIDS epidemic as a public health threat by 2030? The cost and impact of the Fast-Track approach. PLoS ONE. 2016;11(5):e0154893. doi:10.1371/jour nal.pone. 0154893 .

5. UNAIDS. How AIDS changed everything. MDG6: 15 years, 15 lessons of hope from the AIDS response. Geneva; 2015.

6. UNAIDS. On the Fast-Track to end AIDS by 2030. Focus on location and population. Geneva; 2015.

7. Alfvén T, Erkkola T, Ghys PD, Padayachy J, Warner-Smith M, Rugg D, De Lay P. Alfven T, et al. Global AIDS reporting-2001 to 2015: lessons for monitoring the Sustainable Development Goals? AIDS Behav 2016. doi:10.1007/s10461-016-1662-9

8. Jain S, Zorzi N. Investing for impact- the Global Fund approach to measurement. AIDS Behav. 2016. doi:10.1007/s10461-016$1620-6$

9. Akinwande O, Bashorun A, Azeez A, Agbo F, Dakum P, Abimiku A, Bilali C, Idoko J, Ogungbemi K. A decade of monitoring HIV epidemics in Nigeria: status and plans for post-2015. AIDS Behav. 2016. doi:10.1007/s10461-016-1603-7

10. Dumchev K, Varetska O, Kuzin I. Evolution of monitoring and evaluation of the HIV response in Ukraine: setting the stage for evidence-based health care. AIDS Behav. 2016. doi:10.1007/ s10461-016-1571-y

11. Rice BD, Yin Z, Brown AE, Croxford S, Conti S, De Angelis D, Delpech VC. Monitoring of the HIV epidemic using routinely collected data: the case of the United Kingdom. AIDS Behav. 2016. doi:10.1007/s10461-016-1604-6 
12. Low-Beer D, Beusenberg M, Hayashi C, Mamahit A, GarciaCalleja T, Babovic T, Marsh K, Hirnschall G. Monitoring treatment and the health sector cascade: from treatment numbers to impact. AIDS Behav. 2016 (Submitted).

13. Idele P, Hayashi C, Porth T, Mamahit A, Mahy M. Prevention of mother-to-child transmission of HIV and paediatric HIV care and treatment monitoring: from measuring process to impact and elimination of mother-to-child transmission of HIV. AIDS Behav. 2016. doi:10.1007/s10461-016-1670-9

14. Gall J, Sabin K, Erkkola T, Sabin M, Frescura L, Toskin I. Key population monitoring-current challenges and issues. AIDS Behav. 2016 (Submitted).

15. Torres MA, Gruskin S, Buse K, Erkkola T, Bendaud V, Alfvén T. Monitoring HIV-related laws and policies: lessons for AIDS and global health post-2015. AIDS Behav. 2016. doi:10.1007/s10461016-1621-5

16. Smith J, Mallouris C, Lee K, Alfvén T. The role of civil society organizations in monitoring the global AIDS response. AIDS Behav. 2016. doi:10.1007/s10461-016-1579-3

17. Vollmer S, Harttgen K, Alfven T, Padayachy J, Ghys PD, Bärnighausen T. The HIV epidemic in sub-Saharan Africa is ageing: evidence from the Demographic and Health Surveys in sub-Saharan Africa. AIDS Behav. 2016. doi:10.1007/s10461-016-1591-7

18. Ctausen Nielsen R, Luengo-Oroz M, Mello MB, Pdz J, Pantin C, Erkkola, TJ. Social media monitoring of discrimination and the HIV epidemic. AIDS Behav. 2016 (Submitted).
19. UNAIDS. Ambitious treatment targets: writing the final chapter of the AIDS epidemic. Geneva; 2014.

20. WHO. Consolidated strategic information guidelines for HIV in the health sector. Geneva; 2015.

21. WHO. Global health sector response to HIV, 2000-2015. Geneva; 2016.

22. Garnett GP, Hallett TB, Takaruza A, Hargreaves J, Rhead R, Warren M, Nyamukapa C, Gregson S. Providing a conceptual framework for HIV prevention cascades and assessing feasibility of empirical measurement with data from east Zimbabwe: a case study. Lancet HIV. 2016;3:e297-306.

23. UNAIDS. Information and communications technologies. Engaging the private sector and communities in HIV programmes with gay men and other men who have sex with men. Geneva; 2016.

24. UNAIDS. Harnessing the power of technology for social transformation. https://unaids-ap.org/2014/10/27/harnessing-the-power-oftechnology-for-social-transformation/. Accessed 23 Dec 2016.

25. Partnership in Statistics for Development in the 21st Century (PARIS21). http://www.paris21.org/. Accessed 23 Dec 2016.

26. Health data collaborative. https://www.healthdatacollaborative. org/. Accessed 23 Dec 2016. 